\title{
Causes and consequences of individual variation in animal movement
}

\author{
Allison K. Shaw (10
}

\begin{abstract}
Animal movement comes in a variety of 'types' including small foraging movements, larger one-way dispersive movements, seasonally-predictable round-trip migratory movements, and erratic nomadic movements. Although most individuals move at some point throughout their lives, movement patterns can vary widely across individuals within the same species: differing within an individual over time (intra-individual), among individuals in the same population (inter-individual), or among populations (inter-population). Yet, studies of movement (theoretical and empirical alike) more often focus on understanding 'typical' movement patterns than understanding variation in movement. Here, I synthesize current knowledge of movement variation (drawing parallels across species and movement types), describing the causes (what factors contribute to individual variation), patterns (what movement variation looks like), consequences (why variation matters), maintenance (why variation persists), implications (for management and conservation), and finally gaps (what pieces we are currently missing). By synthesizing across scales of variation, I span across work on plasticity, personality, and geographic variation. Individual movement can be driven by factors that act at the individual, population, community and ecosystem level and have ramifications at each of these levels. Generally the consequences of movement are less well understood than the causes, in part because the effects of movement variation are often nested, with variation manifesting at the population level, which in turn affects communities and ecosystems. Understanding both cause and consequence is particularly important for predicting when variation begets variation in a positive feedback loop, versus when a negative feedback causes variation to be dampened successively. Finally, maintaining standing variation in movement may be important for facilitating species' ability to respond to future environmental change.
\end{abstract}

Keywords: Context-dependent, Dispersal kernel, Environmental change, Foraging ecology, Movement ecology, Nomadism, Partial migration, Personality, Plasticity, Population dynamics, Range expansion, Sex-biased dispersal

\section{Introduction}

Movement is ubiquitous; few organisms die in the exact location they were born having never left. The effects of movement have impacts at almost all ecological levels, affecting moving individuals themselves, shaping the distribution and structure of populations, interspecific and intraspecific interactions, and the flow of nutrients, propagules and pathogens across ecosystems. Animal movement comes in a variety of 'types' from daily foraging movements, one-way dispersive movements tied to reproduction, seasonally-predictable round-trip migratory movements, and less predictable erratic nomadic movements [1-3].

Correspondence: ashaw@umn.edu

Department of Ecology, Evolution, and Behavior, University of Minnesota, St. Paul, MN 55108, USA

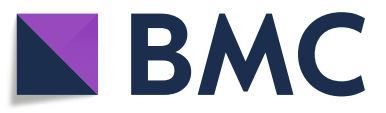

One common thread among these movement types is that individuals vary in their movement behavior. Although movement variation is clearly important, it is often viewed as secondary to understanding 'typical' movement patterns (Additional file 1), and despite having several frameworks for thinking about movement patterns $[2,3]$, we lack frameworks for systematically understanding movement variation. Furthermore, studies of movement variation tend to be siloed by the scale where variation occurs: intra-individual studies discuss flexibility (e.g., plastic or conditional strategies), inter-individual studies focus on stable differences (e.g., sex or personality), and interpopulation studies refer to population-based differences driven by geographic variation.

The practice of studying the average before variance is representative of other biological topics as well. For plants,

(c) The Author(s). 2020 Open Access This article is distributed under the terms of the Creative Commons Attribution 4.0 International License (http://creativecommons.org/licenses/by/4.0/), which permits unrestricted use, distribution, and reproduction in any medium, provided you give appropriate credit to the original author(s) and the source, provide a link to the Creative Commons license, and indicate if changes were made. The Creative Commons Public Domain Dedication waiver (http://creativecommons.org/publicdomain/zero/1.0/) applies to the data made available in this article, unless otherwise stated. 
predictive models are typically based only on average seed dispersal parameters, and a recent review calls for greater attention to how variance in dispersal influences population and community dynamics [4]. Individual differences have also broadly been ignored in studies of ecological niches until relatively recently [5]. Similarly, most experimental studies of climate change focus on mean change and fail to include extreme climate events (and often inadvertently reduce climate variability as a whole) despite evidence that the future will bring increased climate variability [6].

Other areas of ecology have made strides in incorporating averages and variation. In disease ecology most populationlevel analyses focus on an average value of infectiousness, yet it is clear that individual differences can play a critical role in disease spread [7]. For example, sexually-transmitted and vector-borne pathogens follow a 20/80 rule with $20 \%$ of hosts causing $80 \%$ of the transmission events [8]. Thus, there is now recognition of this heterogeneity in the field: the concept of superspreaders, individuals that cause disproportionate amount of new infections [7]. In behavioral ecology, it is recognized that there is behavioral variation both within individuals over time and across individuals. Dingemanse et al. [9] refer to these as 'plasticity' and 'personality' respectively, arguing that these are complementary aspects of individual behavior and shows how behavioral reaction norms can be used to measure differences in each component as well as their interaction.

Here I present an overview of variation in animal movement (Fig. 1, Table 1). I focus on drawing parallels across what I call 'types' of movement: dispersal, foraging, migration, and nomadism. Note that these four types are all well-studied (Additional file 1) but are neither exhaustive of all movement (e.g., escape movements) nor mutually exclusive (e.g., an individual may both disperse and migrate at different points in its life). I aim to understand 'variation', i.e., differences across individuals within species. Variation can occur at many so-called 'scales' (Fig. 2). For example, a single individual may exhibit different movement over its lifetime (intra-individual variation), or individuals with different fixed movement strategies may coexist in the same population (inter-individual), or all individuals within one population may exhibit the same movement strategy, with variation across populations for the species (inter-population). This review encompasses all of these scales. Although many of the patterns described may also apply to interspecific movement variation, that aspect is not covered by this review. Below, I first describe movement variation causes (what factors contribute to individual variation), patterns (what movement variation looks like), and consequences (why variation matters), using non-exhaustive examples from different movement types (dispersal, foraging, migration, nomadism) and scales (intra-individual, inter-individual, inter-population). Finally, I describe movement variation maintenance (how variation persists), implications (for conservation and management), and gaps (what pieces we are currently missing).

\section{Causes: what factors contribute to individual differences in movement?}

\section{Intraspecific interactions}

Differences in intraspecific interactions can drive individual differences in movement (Fig. 1a). For example, competition can favor increased dispersal at high densities [17, 18]. More nuanced density-dependent dispersal patterns may arise, e.g. when dispersal is tied to locating mates, with males being more likely to settle in areas with low male and high female density $[19,20]$. Thus, variation in dispersal may be due in part to variation in local population dynamics. Social hierarchies can lead to differential dispersal or migration based on dominance [21] and social context can drive different migration patterns when migration is socially learned [22]. Social context can also shape foraging strategies in groups where producers (searching for resources) and scroungers (exploiting resources that others find) each do best when they are in the minority, favoring strategy variation at the group level [23]. Finally, differences in position within a population or group can also lead to varaition in movement. For example, group position can be tied to foraging strategy: producers are often at the edge and scroungers in the group core $[24,25]$. Similarly, individuals on the edge of a spreading population often are more dispersive than those at the population core $[11,26]$.

\section{Interspecific interactions}

Differences in interspecific interactions can contribute to individual movement variation, most often at the interpopulation scale. Dispersal [27], migration [28] and nomadism [29], can each help individuals escape infection from local build-up of parasites or pathogens. Conversely, infected individuals can be manipulated by their parasites to disperse more [30] or have a higher activity level [31], to increase contact with new hosts. In these cases, individual movement varies based on the local presence/absence of parasites and pathogens. Differences in predation risk can similarly drive differences in dispersal [32] or migration [33], leading to individual movement variation at the species level. On the other side of this relationship, predators can adjust their movement patterns based on their particular prey. For example, individuals that specialize on migratory prey may migrate themselves while individuals that specialize on non-migratory prey are non-migratory [34], causing inter-population movement variation. Finally, differences in food availability can drive whether [35] and when [14, 36] species migrate, and where nomads move [37]. Individuals may also exhibit near-far searching 
(a) CAUSES

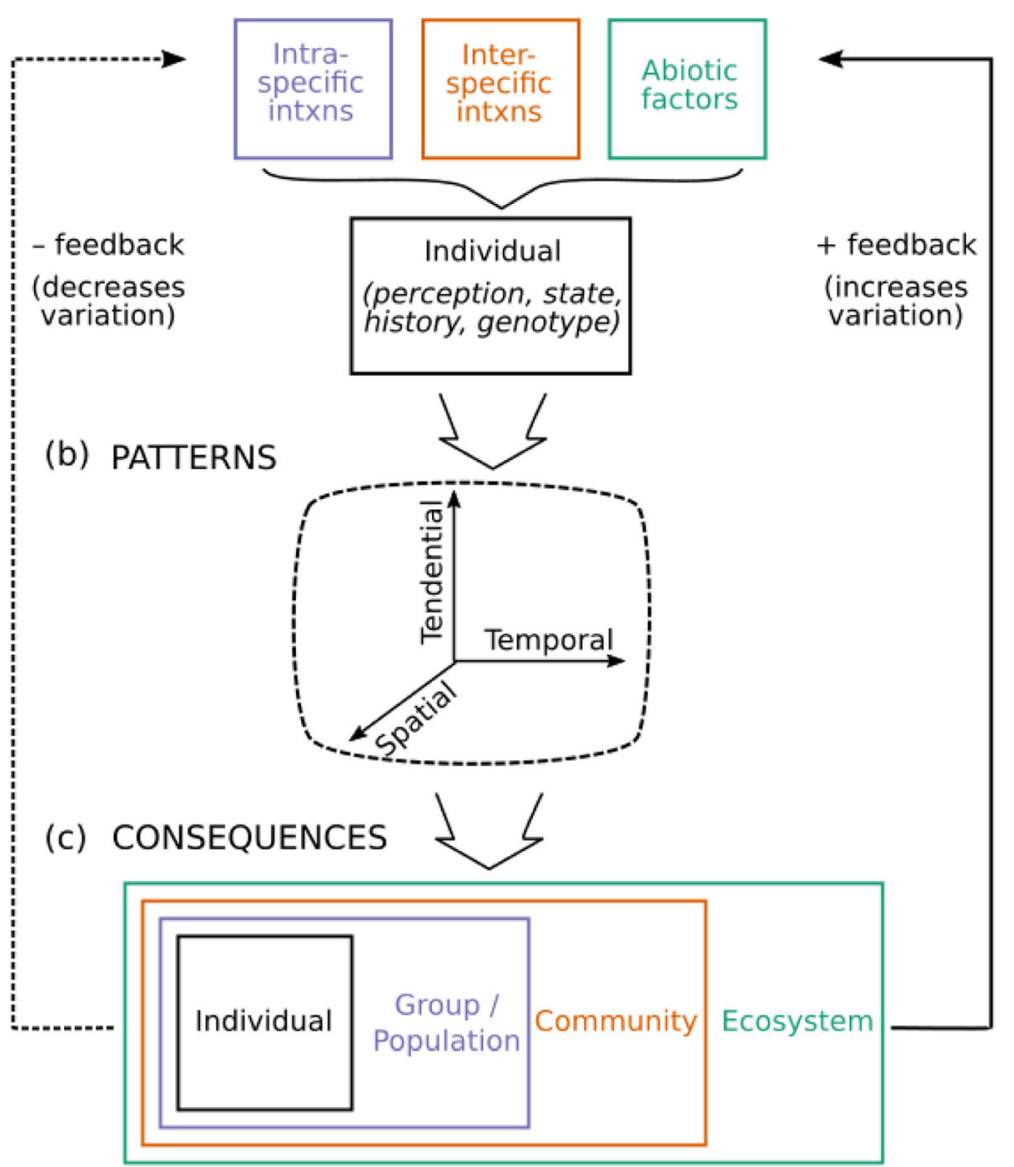

Fig. 1 Schematic of the causes, patterns and consequences of movement variation. a External factors (environment) are perceived by an individual, and taken in combination with its genotype, internal state and history to determine the movement response, (b) movement can vary along three 'axes' (whether to move, when to move, and where to move), and (c) movement first impacts the individual before potentially scaling up to affect the population, community and ecosystem. While causes often act in parallel, consequences are typically nested. Variation in any of the causes (or their interaction) can contribute to variation in movement, and moving in turn can feed back to affect variation if a consequence of moving is increasing variation in the causes of movement (positive feedback, solid arrow) or decreasing said variation (negative feedback, dashed arrow)

when foraging; moving locally in areas with good forage and moving longer distances otherwise [38].

\section{Abiotic factors}

Differences in local abiotic conditions contribute to individual movement variation (again, often at the interpopulation scale; Fig. 1a). Increasingly worse conditions can favor increased movement when moving facilitates escape away from these areas. For example, movement by irruptive nomads can be triggered by an abrupt change in conditions [39], while migration can be driven by seasonally unfavorable conditions like deep snow [40], or rough storms [41, 42]. Variation in these conditions spatially or temporally can lead to variation in movement. Alternatively, increasingly good conditions can favor increased movement when moving facilitates individuals' ability to make the journey to a new location successfully. For example, moving can be less costly under higher precipitation [43], warmer temperatures [44], or favorable wind directions [45]. More broadly, variation in habitat features [46] can lead to differences in individual movement decisions, while unpredictability in conditions can favor nomadic movements [2].

\section{Individual traits}

Each of the above intra- and inter-specific interactions and abiotic factors are filtered through the individual to shape its movement pattern (Fig. 1a). Variation in any of the causes (or their interaction) can contribute to variation in movement. Movement is thus determined by an individual's perception of external factors, in combination with its genotype, and internal state (status, history). Some individual traits are more stable while others are more labile. 


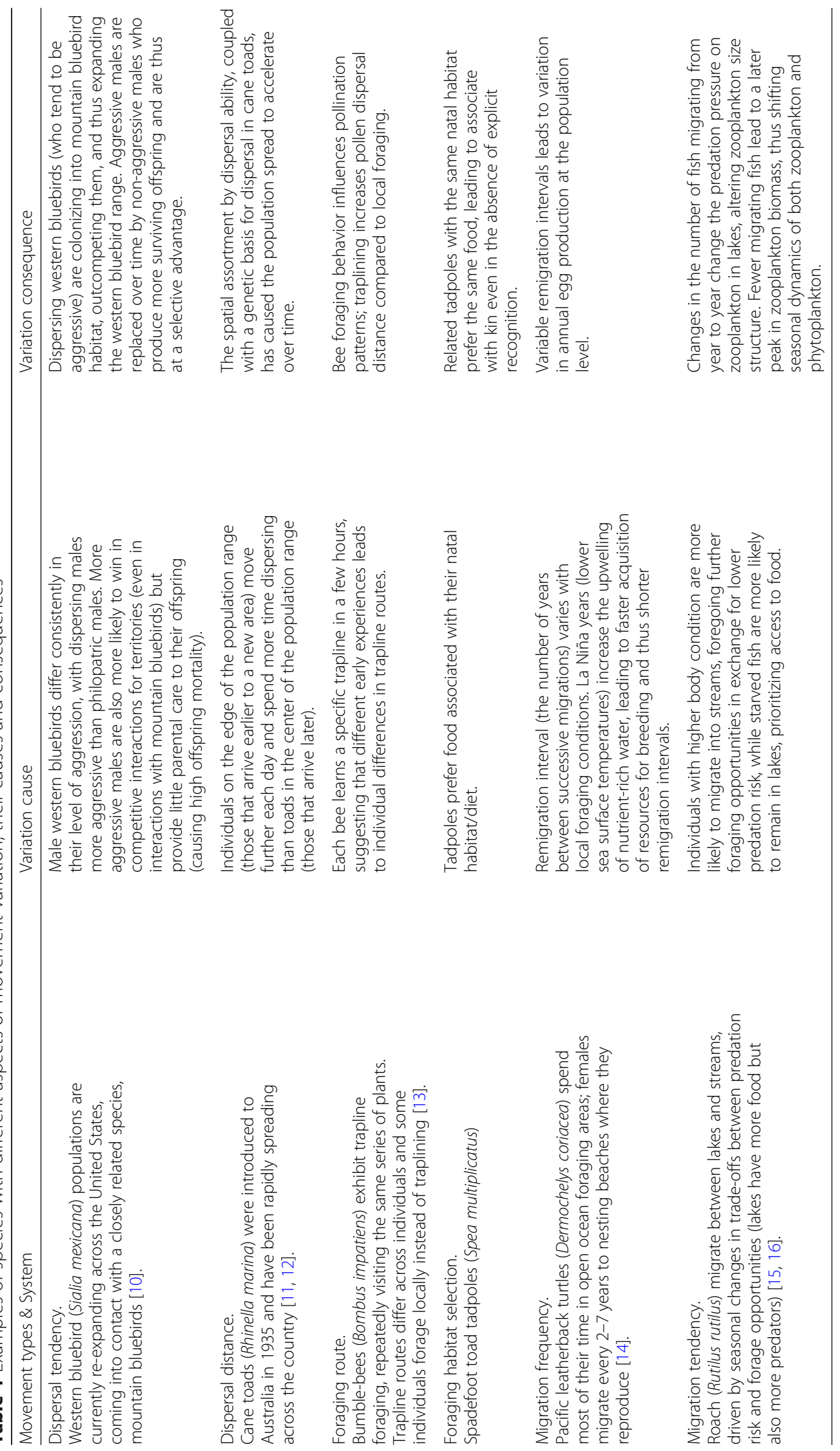


(a) INTRA-INDIVIDUAL

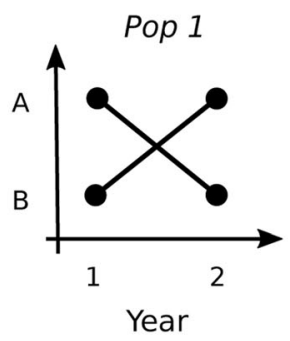

(b) INTER-INDIVIDUAL

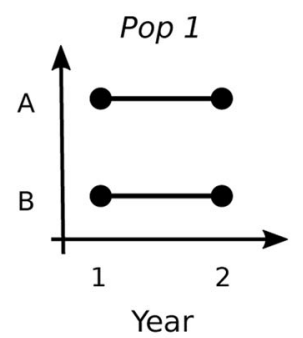

(c) INTER-POPULATION
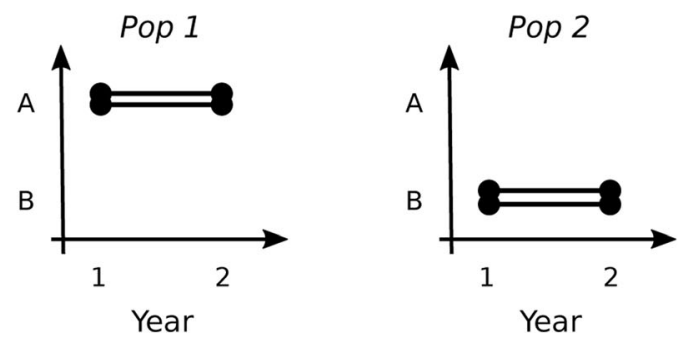

Fig. 2 Individual differences in movement can occur at several scales. Each line represent one individual that displays one of two different movement behaviors (A or B) across each of two years, for two different populations. Differences can occur (a) within the same individual over time, (b) among individuals within a population, or (c) among populations of individuals

Traits that are relatively stable contribute to inter-individual differences in movement. For example, sex-specific costs of moving or energetic requirements (associated with reproduction) can lead to sex-biased movement in each dispersal [47], foraging [48], migration [49], and nomadism [50]. The location where an animal was born (natal habitat) can also shape movement decisions through a preference for similar habitat when foraging [51] or dispersing (natal habitat preference induction [52]), or a tendency to return back to the same exact location after migration [53]. Similarly, early life conditions shape which cues an individual uses to navigate [54]. Movement differences can also derive from differences in individual behavioral types where baseline activity, aggression, boldness and sociality affect an individual's movement ability [55], social foraging tactic [56], tendency to disperse [57] or to migrate [58]. Relatively stable individual differences can either derive from differences in development (i.e., morphs or castes where only some individuals have wings [59], or are gregarious and highly mobile [60]), or be rooted in genetic differences in a movement-related trait [61].

Traits that are more labile (varying through an individual's lifetime) also contribute to intra-individual variation in movement. For example, costs and benefits to moving can vary with age or life history stage, leading to age- or stage-specific patterns of dispersal [62], nomadism [63], or migration [53]. Individual body size, condition, or degree of hunger/satiation can also contribute to foraging movements [64] as well as tendency to migrate $[15,65,66]$ or disperse [67]. Infection status can influence movement at several levels [68] with infected individuals being generally less active [69], less likely to disperse [70], or less likely to migrate [71], or the opposite, with infected individuals actually dispersing more [72]. Finally, movement can vary based on information usage, where individuals migrate following whichever route they first learned [73], or do trapline foraging based on learned habitat patches [13].

\section{Pattern: what is individual variation in movement behavior?}

Individual variation in movement can manifest in different ways (Fig. 1b, Table 1). Variation that is common, often gets referred to with specific terminology (e.g., partial migration). Although terminology can be useful for linking studies within a movement type, this terminology can inhibit cross-talk among studies on different types of movement. Individual variation in movement can be characterized by three 'axes': tendential (whether), temporal (when), and spatial (where), common to all types of movement (dispersal, foraging, migration, nomadism).

\section{Tendential}

First, individuals may vary in movement tendency, either with only some individuals moving while others do not, or with variation in how responsive individuals are to stimuli for movement. For example, 'partial migration' describes some individuals migrating in a given season while others do not [74, 75], and partial nomadism describes some individuals being nomadic while others are not [39]. In contrast, foraging movements are often named bimodally with individuals either adopting a sedentary ('sit-and-wait') or an active ('search') strategy [76]. Differences in individual tendency to disperse are described in terms of a dispersal probability or a dispersal rate. 


\section{Temporal}

Second, individuals can vary in temporal aspects of movement: the frequency and timing of their movements, and how much time they spend on movement compared to other activities. In some cases, partial migration is driven by differences in individual migration frequency (or staggered frequency), rather than tendency [66]. For group foragers, again there is often a bimodal strategy in movement timing with 'producers' actively searching for resources while 'scroungers' exploit resources once they are uncovered by others [23].

\section{Spatial}

Finally, individuals can vary in spatial aspects of movement, including distance, direction, area covered, and path tortuosity. These aspects can be quantified by metrics that measure turn angle correlations, stability of home range, and net squared displacement (the distance between an individual's starting and current locations), as well as final location, which can be quantified in terms of habitat or resource preference [77, 78]. Some species exhibit 'differential migration', with individual variation in the distances traveled, often based on individual traits [79, 80]. In other species, individuals starting from the same location differ in their foraging routes with consistent differences in departure angles and terminal points [81]. Individuals can also differ in the distance traveled while foraging or searching; 'Lévy flights' describe searching behavior where the distance traveled at each time step varies according to a power law [82]. Variation in dispersal distance is often summarized by a 'dispersal kernel', $k(x, y)$, which describes the probability that an individual starting at location $x$ will travel to location $y$. Dispersal kernels aggregate variation, either by tracking dispersal at the population level (summing across all individuals and their differences) or by effectively assuming that all individuals are identical but vary in the same way.

\section{Consequences: why does movement variation matter? \\ Individual}

At the individual level, variation in movement leads to variation in the costs and benefits in terms of growth, survival and reproduction to individuals (Fig. 1c). All behaviors have costs and benefits; movement is no different. On the whole, if movement is favored by selection, we should expect the benefits of observed movement strategies to outweigh the costs, with the favoring of movement strategies that reduce costs [83]. When individuals differ in their movement, one possible outcome is no net difference in costs and benefits across individuals; e.g., if some individuals experience simultaneously increased costs and increased benefits compared to others. For example, foraging mode influences energy expenditure, where widely foraging individuals both expend and take in more energy than sit-and-wait ones
[84]. Alternatively, individuals may trade off costs and benefits across different life history currencies. For example, some migrants trade off the benefit of lower predation risk at the cost of lower foraging opportunities [85] compared to those that stay. Similarly, in species with breeding migrations, migrants trade off survival cost with the benefit of reproduction $[66,86]$. A third possibility is that individuals vary in their needs and thus experience costs and benefits differently. For example, pregnant or lactating female mammals have increased energetic needs compared to nonlactating individuals and may adjust their movement patterns accordingly $[49,87]$.

\section{Group and population}

For group-living species, individual differences can impact group dynamics (Fig. 1c). In highly mobile species, movement variation can challenge group cohesion if individuals travel at different speeds [88] or prefer to move in different directions [89]. Individual heterogeneity in movement can also increase group fragmentation [87] and result in smaller groups, which in turn can affect predation risk and ability to respond to changing environments [90]. Conversely having naive individuals in the same group as individuals with a preferred direction can facilitate decision-making about the direction of travel [89] and facilitate learning of a preferred direction by naive individuals [91]. In more sedentary (colonial) species, variation in movement related to labor partitioning can increase colony efficiency (e.g., eusocial insect castes [92]).

Individual differences in movement also scale up to impact populations. When variation occurs among individuals for a given year (rather than among years for a given individual), movement variation can increase the 'footprint' of a population at a snapshot in time. In the extreme, a seemingly stable population distribution can actually be composed of a set of highly nomadic individuals; in any location the identity of individuals changes continuously while the number present remains constant [2]. Given that most dispersing individuals travel short-distances, variation in dispersal distance can be critical for shaping genetic structure and maintaining population connectivity $[93,94]$. Thus, movement variation can facilitate gene flow, e.g., if a few individuals occasionally move between otherwise distinct populations to breed [95]. However, if the average dispersal distance is already quite high dispersal variation can decrease inter-patch movements, leading to decreased population connectivity and decreased population size [96]. Individual differences in movement can shape different aspects of population invasion across a landscape, from the probability of colonization (rare longdistance dispersal facilitate introductions [97]), to the dynamics of spread (density-dependent dispersal can cause inter-annual fluctuations in spread [98]), to whether spread occurs at a constant or an increasing rate (fat-tailed kernels and dispersal evolution can accelerate spread [12, 99]). 
Finally, variation in movement can also lead to variation in infectiousness [100] which can simultaneously lead to higher likelihood of a disease being eradicated as well as larger but rare outbreaks [7].

\section{Community and ecosystem}

Intraspecific movement variation can scale through the population level to impact community and ecosystem processes (Fig. 1c). In contrast, individuals differences in movement that are not detectable at the population level, should be less likely to scale up to impact community or ecosystem dynamics.

Movement variation can have consequences for symmetric pairwise species interactions (e.g. competition, mutualism). For example, variation in dispersal ability linked to behavioral type (e.g., aggression) can increase interspecific competition [10]. However, dispersal variation driven by environmental stochasticity can actually promote the coexistence of two competitors with otherwise identical niches [101]. In terms of mutualisms, pollinator foraging patterns vary with landscape structure, which can in turn impact the pollination rates they provide to plants [102]. Similarly, variation in animal dispersal can drive the spatial patterns of seed rain for animal-dispersed plant species [103].

Movement variation can also have consequences for asymmetric pairwise species interactions (e.g. predatorprey, host-pathogen). For example, many migratory species serve as important prey items for other species [104], so variation in the number of migrants across years could impact food availability and potentially predator population dynamics. Conversely, variation in the number of predators migrating can provide release for prey, leading to changes in both the abundance and seasonal dynamics of prey [16]. Migratory species can also bring parasites and pathogens from diverse locations, leading to outbreaks at stopover sites [105], thus variation in migration timing within species (e.g., degree of synchrony) can drive these infection dynamics [106].

Finally, movement variation can have implications for ecosystem-level processes. Individuals also move around nutrients as they move (foraging in some locations and defecating in others); thus movement variation can cause variable nutrient inputs across ecosystems [107]. As migrants die throughout migration their carcasses become important nutrient sources, and serve as links across ecosystems [108]. Thus variation in migrant numbers across space or over time can lead to nutrient deficits [109].

\section{Maintenance: what preserves movement variation?}

The maintenance of movement variation, like variation in any trait, depends on the level at which variation is encoded. Individual movement differences may be due to different genotypes, in which case they would be maintained by a balance of drift, immigration/emigration, mutation, and selection, as for any other genetic trait. The same genotype may also generate different movement behaviors either across individuals, depending on how they develop (developmental plasticity [110]) or within the same individual over time (activational plasticity [110]). Environmental variation in particular is viewed as major driver of behavioral plasticity, yet behavior itself can 'construct' how environmental variation is perceived by an individual [111]. Thus, movement itself feeds back to influence the degree of variation experienced by an individual (Fig. 1, arrows), making disentangling sources of variation a key challenge in understanding movement variation maintenance. Genetic variation in any 'construction' trait (such as movement) is also expected to lead to maintenance of plasticity [111].

The fact that movement can simultaneously be affected by and have effects at many different ecological levels (Fig. 1), leaves open the potential for feedback loops between cause and consequence. This is perhaps easiest to see at the individual and population levels. For example, in species that migrate to reproduce, individuals often migrate once they have accumulated enough energetic resources to breed and do not migrate otherwise [66]. Here, migration has a negative feedback (Fig. 1, dashed arrow): by migrating and breeding, individuals expend these resources thus reducing their probability of migrating the next year. As a second example, in a growing and expanding population, individual dispersal variation can lead to spatial sorting, with individuals dispersing the longest distances ending up at the population edge $[112,113]$. Assortative mating among these edge individuals may then lead to offspring that disperse even longer distances (The 'Olympic village effect'; [114]), thus increasing movement variation within the population, in a positive feedback loop (Fig. 1, solid arrow). Examples can also be found at the community and ecosystem level: broadly, environmental predictability shapes movement which in turn can both increase and decrease environmental predictability in feedback loops [115].

Given the role of the environment in shaping movement variation, any change (natural or anthropogenic) to the degree of environment variation stands to influence movement variation. Climate is increasing in variability and current projections show an increase in extreme climate events [116]. Since environmental variation typically begets movement variation, this should increase variability in movement behavior. Anthropogenic disturbances have been shown to increase movement variation by increasing the frequency of switching between traveling and resting [117] and the degree of asymmetry in dispersal (where emmigration and immigration rates differ) [118]. Conversely, other forms of anthropogenic change may decrease environmental variability (e.g., homogenization of conditions through food supplementation), which can shift selective pressures on movement behavior, causing 
knock-on effects at the population level [119]. Human activities can also move species directly, typically increasing movement variation, by either accidentally introducing alien species [120] or moving individuals as part of an assisted migration conservation strategy [121]. Finally, existing variation in movement behaviors like dispersal can shape the degree to which species are able to respond to environmental change [122].

\section{Management and conservation implications}

What are the conservation and management implications of movement variation? Conservation efforts require knowledge about which habitats should be protected for a given species (e.g., aquatic versus terrestrial [123]), and benefit from knowledge about what relative effort to allocate to different habitat types (within-stream vs ocean-stream connections [124]). Management decisions about networks of protected areas are based on estimates of genetic structure and population connectivity, which are both driven by variation in movement $[94,95,125]$. Understanding the mechanisms linking dispersal variation to population spread can inform eradication efforts for invasive species [126].

The concept of conserving movement strategies has been advocated for in the case of migratory species which provide key ecosystem functions [104] and is likely important for other types of movement. We should consider conserving variation in movement for its own sake. Maintaining standing variation in movement may facilitate species' ability to track changing climate environments, and improve resilience in responding to anthropogenic change [127]. Since movement variation is an interaction among genotype, individual, and environment (Fig. 1), this may be achievable by conserving both genetic diversity and habitat heterogeneity. It is unclear if there are ways to conserve movement variation driven by individual differences that are independent of genotype and environment; this idea could be explored in future work. A more nuanced conservation strategy would be to first determine at which scale variation is occurring (intra-individual, inter-individual, inter-population) and target strategies accordingly. Minimally movement variation should be accounted for when weighing different strategies. For example, loss of movement variation should be considered one of the impacts of losing genetic diversity.

\section{Gaps: what are we missing?}

I have aimed for this review to be broad - spanning across both types of movement (dispersal, foraging, migration, nomadism) and scale of variation (intra-individual, inter-individual, inter-population). My hope is that researchers interested in variation in only one of these categories will gain new insights by seeing how variation has been considered in other categories.
As a whole, we have a better understanding of the causes of movement variation than of the consequences. Within consequences, the effect of individual movement variation at the community and ecosystem levels is poorly studied compared to its impact at the population level. This may be because individual differences at these higher levels typically need to scale through the population level to have an effect (Fig. 1). That is, individual differences in movement that do not lead to population variation (e.g., only some individuals migrate but the proportion migrating is constant from year to year), are less likely to impact community or ecosystem dynamics. However, this may not always be the case: if individuals differ in certain traits (e.g., stochiometry, consumption rates), movement variation may impact community/ecosystem dynamics even without causing population variation. Thus we have a need for empirical studies to quantify when individual variation affects community and ecosystem processes as well as theoretical studies to predict under what conditions individual variation is most likely to impact community and ecosystem processes. Feedback loops between empirical and theoretical studies will serve to move this research forward as well [4].

As a first step, reporting different forms of variation in collected data (e.g. both the standard deviation in movement traits as well as outliers), will contribute to a broader scientific culture of accounting for movement variation [4]. Second, collected data can be used to account for variation within and across classes of individuals simultaneously, e.g., by characterizing male and female dispersal kernels [128], rather than a single dispersal kernel or sex-specific fixed dispersal distances. Finally, future studies should consider interactions between variation at different scales, starting with experimental design and analysis. For example, the framework of behavioral reaction norms from behavioral ecology generally [9] can be used to look at interactions between intra-individual and inter-individual differences in movement ecology specifically.

Future theoretical studies could help shape the way we think about movement variation in several ways. First, theoretical frameworks could be developed to determine whether there are certain characteristics of a biological system or scenario that could be used to predict when movement variation is most likely to be important. Such frameworks could help guide which future empirical studies should focus on variation and when it can safely be ignored. Second, theory could be developed to predict when variation begets more variation versus when it has a dampening effect (Fig. 1). Although movement variation should be relatively easy to implement in theoretical studies, most models take a simplistic approach to variation [90]. Thus, using models to explore a greater diversity of variation forms could greatly improve our 
understanding of the causes and consequences of movement variation. A major challenge in future theoretical work is developing techniques that enable models to capture variation without sacrificing too much analytic tractability, which reduces interpretability [129]. For example, current theory can account for stable individual differences or labile individual strategies separately, but accounting for both is most often done via individualbased models which can make nuanced interpretations challenging.

Future empirical studies could help fill gaps in our knowledge of existing movement variation. Across movement types, we have a better understanding of variation in dispersal and migration than we do for nomadism (Table 1); somewhat ironic given the perception of nomadism as a highly variable movement pattern. We also have a better conceptual understanding of variation in negative interspecific causes and consequences (e.g., predator-prey, host-parasite) than in positive interspecific interactions (e.g., mutualisms, facilitation), mirroring a broader trend in interspecific interaction studies [130]. Empirical work that compares movement variation in lab-based and field-based studies can help us understand when there are positive vs negative feedback loops in variation. One of the appeals of lab system is that they present a more controlled (and less variable) environment. Thus, comparing these will determine when effects measured in the lab will be amplified (versus dampened) in a variable field setting, helping to extrapolate from lab-based studies on variation to generate field-based predictions.

\section{Conclusions}

Individual variation in movement is almost as ubiquitous as movement behavior itself. However, our understanding of the causes and consequences of movement variation lags far behind our understanding of 'typical' movement patterns, in part because understanding differences requires more data and longer-term studies than understanding averages. Papers in the past few years have called for a better understanding of individual differences impacting movement in terms of personality [55] and collective movements [90]. Here, I have highlighted the need to understand variation in animal movement at all scales (including these) and I have presented a framework (Fig. 1) for thinking about movement variation that draws parallels across different movement types (dispersal, foraging, migration, nomadism). Unfortunately, the areas where variation is understudied are particularly those areas where movement variability can have critical impacts: at community and ecosystem levels. This lack of understanding is likely because the consequences of movement variation are nested across levels, with individual differences only having an indirect impact at the community and ecosystem level, acting via their impact on the population level (Fig. 1). Developing theory that explores a broader range of variation in movement patterns could be especially useful in understanding consequences across these levels. This review, in conjunction with a similar recent call from the plant perspective [4] highlights the immediate need to understand how individual movement differences scale up beyond the population level, across all kinds of organisms.

\section{Supplementary information}

Supplementary information accompanies this paper at https://doi.org/10. 1186/s40462-020-0197-x.

Additional file 1. Trends in studying movement variation over time.

\section{Acknowledgments}

I thank Maria Delgado, Orr Spiegel, Claire Teitelbaum, and anonymous reviewers for helpful feedback on the manuscript, the 2019 Gordon Research Conference on Movement Ecology of Animals for stimulating ideas, and the National Center for Faculty Development \& Diversity Faculty Success Program for helping me develop the tools to write this paper.

\section{Author's contributions}

AKS conceived of, and carried out, the work, and wrote the manuscript. The author read and approved the final manuscript.

\section{Funding}

This material is based in part upon work supported by the National Science Foundation under Grant No. DEB-1654609 and IOS-1556674 to AKS.

\section{Availability of data and materials}

Not applicable.

Ethics approval and consent to participate

Not applicable.

Consent for publication

Not applicable.

\section{Competing interests}

The author has no competing interests.

Received: 26 June 2019 Accepted: 5 February 2020

Published online: 17 February 2020

\section{References}

1. Heape W. Emigration, migration and nomadism. Cambridge: Heffer and Sons; 1931

2. Mueller T, Fagan WF. Search and navigation in dynamic environments-from individual behaviors to population distributions. Oikos. 2008;117:654-64.

3. Nathan R, Getz WM, Revilla E, Holyoak M, Kadmon R, Saltz D, et al. A movement ecology paradigm for unifying organismal movement research. Proc Natl Acad Sci U S A. 2008:19052-9.

4. Snell RS, Beckman NG, Fricke E, Loiselle BA, Carvalho CS, Jones LR, et al. Consequences of intraspecific variation in seed dispersal for plant demography, communities, evolution, and global change. AoB Plants. 2019; 11:plz016.

5. Bolnick DI, Svanbäck R, Fordyce JA, Yang LH, Davis JM, Hulsey CD, et al. The ecology of individuals: incidence and implications of individual specialization. Am Nat. 2003;161:1-28.

6. Thompson RM, Beardall J, Beringer J, Grace M, Sardina P. Means and extremes: building variability into community-level climate change experiments. Ecol Lett. 2013;16:799-806.

7. Lloyd-Smith JO, Schreiber SJ, Kopp PE, Getz WM. Superspreading and the effect of individual variation on disease emergence. Nature. 2005;438:355-9.

8. Woolhouse MEJ, Dye C, Etard J-F, Smith T, Charlwood JD, Garnett GP, et al. Heterogeneities in the transmission of infectious agents: implications for the design of control programs. Proc Natl Acad Sci. 1997;94:338-42.

9. Dingemanse NJ, Kazem AJN, Réale D, Wright J. Behavioural reaction norms: animal personality meets individual plasticity. Trends Ecol Evol. 2010;25:81-9. 
10. Duckworth RA, Badyaev AV. Coupling of dispersal and aggression facilitates the rapid range expansion of a passerine bird. Proc Natl Acad Sci U S A. 2007; 104:15017-22.

11. Lindström T, Brown GP, Sisson SA, Phillips BL, Shine R. Rapid shifts in dispersal behavior on an expanding range edge. Proc Natl Acad Sci. 2013; 110:13452-6.

12. Phillips BL, Brown GP, Shine R. Evolutionarily accelerated invasions: the rate of dispersal evolves upwards during the range advance of cane toads. J Evol Biol. 2010;23:2595-601.

13. Ohashi K, Thomson JD. Trapline foraging by pollinators: its ontogeny, economics and possible consequences for plants. Ann Bot. 2009:103:1365-78.

14. Saba VS, Santidrián-Tomillo P, Reina RD, Spotila JR, Musick JA, Evans DA, et al. The effect of the El Niño southern oscillation on the reproductive frequency of eastern Pacific leatherback turtles. J Appl Ecol. 2007:44:395-404.

15. Brodersen J, Nilsson PA, Hansson L-A, Skov C, Brönmark C. Conditiondependent individual decision-making determines cyprinid partial migration. Ecology. 2008:89:1195-200.

16. Brodersen J, Nicolle A, Nilsson PA, Skov C, Brönmark C, Hansson L-A. Interplay between temperature, fish partial migration and trophic dynamics. Oikos. 2011;120:1838-46.

17. Denno RF, Peterson MA. Density-dependent dispersal and its consequences for population dynamics. Popul Dyn New Approaches Synth. San Diego: Academic Press; 1995. p. 113-25.

18. Matthysen E. Density-dependent dispersal in birds and mammals. Ecography. 2005;28:403-16.

19. Clarke PMR, Henzi SP, Barrett L, Rendall D. On the road again: competitive effects and condition-dependent dispersal in male baboons. Anim Behav. 2008;76:55-63.

20. Shaw AK, Kokko H. Mate finding, Allee effects and selection for sex-biased dispersal. J Anim Ecol. 2014;83:1256-67.

21. Gauthreaux J Sidney A. The ecological significance of behavioural dominance. Soc Behav. 1978. p. 17-54.

22. Jesmer BR, Merkle JA, Goheen JR, Aikens EO, Beck JL, Courtemanch AB, et al Is ungulate migration culturally transmitted? Evidence of social learning from translocated animals. Science. 2018;361:1023-5.

23. Barnard CJ, Sibly RM. Producers and scroungers: a general model and its application to captive flocks of house sparrows. Anim Behav. 1981;29:543-50.

24. Barta Z, Flynn R, Giraldeau L-A. Geometry for a selfish foraging group: a genetic algorithm approach. Proc R Soc Lond B Biol Sci. 1997;264:1233-8.

25. Flynn RE, Giraldeau L-A. Producer-scrounger games in a spatially explicit world: tactic use influences flock geometry of spice finches. Ethology. 2001;107:249-57.

26. Chuang A, Peterson CR. Expanding population edges: theories, traits, and trade-offs. Glob Change Biol. 2016;22:494-512

27. Boulinier T, McCoy K, Sorci G. Dispersal and parasitism. Dispersal. Oxford: Oxford University Press; 2001. p. 169-79.

28. Loehle C. Social barriers to pathogen transmission in wild animal populations. Ecology. 1995;76:326-35

29. McGlynn TP. The ecology of nest movement in social insects. Annu Rev Entomol. 2012:57:291-308.

30. Lion S, van Baalen M, Wilson WG. The evolution of parasite manipulation of host dispersal. Proc R Soc B Biol Sci. 2006;273:1063-71.

31. Lafferty KD, Shaw JC. Comparing mechanisms of host manipulation across host and parasite taxa. J Exp Biol. 2013;216:56-66.

32. Baines CB, McCauley SJ, Rowe L. The interactive effects of competition and predation risk on dispersal in an insect. Biol Lett 2014:10:20140287-20140287.

33. Hopcraft JGC, Morales JM, Beyer HL, Borner M, Mwangomo E, Sinclair ARE, et al. Competition, predation, and migration: individual choice patterns of Serengeti migrants captured by hierarchical models. Ecol Monogr. 2014;84:355-72.

34. Ford JKB, Ellis GM, Barrett-Lennard LG, Morton AB, Palm RS, Balcomb KC III. Dietary specialization in two sympatric populations of killer whales (Orcinus orca) in coastal British Columbia and adjacent waters. Can J Zool. 1998;76:1456-71.

35. Olsson IC, Greenberg LA, Bergman E, Wysujack K. Environmentally induced migration: the importance of food. Ecol Lett. 2006;9:645-51.

36. Schaffer WM, Elson PF. The adaptive significance of variations in life history among local populations of Atlantic salmon in North America. Ecology. 1975:56:577-90.

37. Mueller T, Olson KA, Fuller TK, Schaller GB, Murray MG, Leimgruber P. In search of forage: predicting dynamic habitats of Mongolian gazelles using satellitebased estimates of vegetation productivity. J Appl Ecol. 2008;45:649-58.

38. Motro U, Shmida A. Near-far search: an evolutionarily stable foraging strategy. J Theor Biol. 1995;173:15-22.
39. Teitelbaum CS, Mueller T. Beyond migration: causes and consequences of nomadic animal movements. Trends Ecol Evol. 2019:34:569-81.

40. Harris G, Thirgood S, Hopcraft JGC, Cromsigt JPGM, Berger J. Global decline in aggregated migrations of large terrestrial mammals. Endanger Species Res. 2009;7:55-76.

41. Kanciruk P, Herrnkind W. Mass migration of spiny lobster, Panulirus argus (Crustacea Palinuridae): behavior and environmental correlates. Bull Mar Sci. 1978;28:601-23.

42. Boyle WA, Norris DR, Guglielmo CG. Storms drive altitudinal migration in a tropical bird. Proc R Soc Lond B Biol Sci. 2010;277:2511-9.

43. Shaw AK, Kelly KA. Linking El Niño, local rainfall, and migration timing in a tropical migratory species. Glob Change Biol. 2013;19:3283-90.

44. Kuussaari M, Rytteri S, Heikkinen RK, Heliölä J, von Bagh P. Weather explains high annual variation in butterfly dispersal. Proc R Soc B Biol Sci. 2016;283: 20160413

45. Walls SS, Kenward RE, Holloway GJ. Weather to disperse? Evidence that climatic conditions influence vertebrate dispersal. J Anim Ecol. 2005:74:190-7.

46. Strandburg-Peshkin A, Farine DR, Crofoot MC, Couzin ID. Habitat and social factors shape individual decisions and emergent group structure during baboon collective movement. eLife. 2017;6:e19505.

47. Greenwood PJ. Mating systems, philopatry and dispersal in birds and mammals. Anim Behav. 1980;28:1140-62.

48. Lewis S, Benvenuti S, Dall'Antonia L, Griffiths R, Money L, Sherratt TN, et al. Sex-specific foraging behaviour in a monomorphic seabird. Proc R Soc Lond B Biol Sci. 2002;269:1687-93.

49. McGuire LP, Boyle WA. Altitudinal migration in bats: evidence, patterns, and drivers. Biol Rev. 2013;88:767-86.

50. Hipkiss $T$, Hörnfeldt $B$, Lundmark $\AA$, Norbäck M, Ellegren $H$. Sex ratio and age structure of nomadic Tengmalm's owls: a molecular approach. J Avian Biol. 2002;33:107-10.

51. Pfennig DW. "Kin recognition" among spadefoot toad tadpoles: a side-effect of habitat selection? Evolution. 1990:44:785-98.

52. Davis JM, Stamps JA. The effect of natal experience on habitat preferences. Trends Ecol Evol. 2004;19:411-6.

53. Quinn TP, Dittman AH. Pacific salmon migrations and homing: mechanisms and adaptive significance. Trends Ecol Evol. 1990;5:174-7.

54. Wiltschko R, Schöps M, Kowalski U. Pigeon homing: wind exposition determines the importance of olfactory input. Naturwissenschaften. 1989;76:229-31.

55. Spiegel O, Leu ST, Bull CM, Sih A. What's your move? Movement as a link between personality and spatial dynamics in animal populations. Ecol Lett. 2017;20:3-18.

56. Kurvers RHJM, Prins HHT, van Wieren SE, van Oers K, Nolet BA, Ydenberg RC. The effect of personality on social foraging: shy barnacle geese scrounge more. Proc R Soc B Biol Sci. 2010;277:601-8.

57. Cote J, Clobert J, Brodin T, Fogarty S, Sih A. Personality-dependent dispersal: characterization, ontogeny and consequences for spatially structured populations. Philos Trans R Soc Lond Ser B Biol Sci. 2010:365:4065-76.

58. Chapman BB, Hulthén K, Blomqvist DR, Hansson L-A, Nilsson J-Å, Brodersen $J$, et al. To boldly go: individual differences in boldness influence migratory tendency: boldness influences migratory tendency. Ecol Lett. 2011;14:871-6.

59. Dixon AFG, Glen DM. Morph determination in the bird cherry-oat aphid, Rhopalosiphum padi L. Ann Appl Biol. 1971;68:11-21.

60. McCaffery A, Simpson SJ, Saiful Islam M, Roessingh P. A gregarizing factor present in the egg pod foam of the desert locust Schistocerca gregaria. J Exp Biol. 1998:201:347-63.

61. Edelsparre AH, Vesterberg A, Lim JH, Anwari M, Fitzpatrick MJ. Alleles underlying larval foraging behaviour influence adult dispersal in nature. Ecol Lett. 2014;17:333-9.

62. Harts AMF, Jaatinen $\mathrm{K}$, Kokko $\mathrm{H}$. Evolution of natal and breeding dispersal: when is a territory an asset worth protecting? Behav Ecol. 2016;27:287-94

63. Loretto M-C, Reimann S, Schuster R, Graulich DM, Bugnyar T. Shared space, individually used: spatial behaviour of non-breeding ravens (Corvus corax) close to a permanent anthropogenic food source. J Ornithol. 2016;157:439-50.

64. Munk P. Foraging behaviour of larval cod (Gadus morhua) influenced by prey density and hunger. Mar Biol. 1995;122:205-12.

65. Pearre S Jr. Eat and run? The hunger/satiation hypothesis in vertical migration: history, evidence and consequences. Biol Rev. 2003;78:1-79.

66. Shaw AK, Levin SA. To breed or not to breed: a model of partial migration. Oikos. 2011;120:1871-9.

67. Burgess SC, Hart SP, Marshall DJ. Pre-settlement behavior in larval bryozoans: the roles of larval age and size. Biol Bull. 2009;216:344-54. 
68. Binning SA, Shaw AK, Roche DG. Parasites and host performance: incorporating infection into our understanding of animal movement. Integr Comp Biol. 2017:57:267-80.

69. Main AR, Bull CM. The impact of tick parasites on the behaviour of the lizard Tiliqua rugosa. Oecologia. 2000;122:574-81.

70. Møller AP, Szép T. The role of parasites in ecology and evolution of migration and migratory connectivity. J Ornithol. 2011;152:S141-50.

71. Johnson PTJ, Stanton DE, Forshay KJ, Calhoun DM. Vertically challenged: how disease suppresses Daphnia vertical migration behavior. Limnol Oceanogr. 2018;63:886-96.

72. Brown CR, Brown MB. Ectoparasitism as a cause of natal dispersal in cliff swallows. Ecology. 1992;73:1718-23.

73. McQuinn $\mathbb{H}$. Metapopulations and the Atlantic herring. Rev Fish Biol Fish. 1997:7:297-329.

74. Chapman BB, Brönmark C, Nilsson J- $\AA$, Hansson L-A. Partial migration: an introduction. Oikos. 2011;120:1761-3.

75. Lack D. The problem of partial migration. Brit Birds Lond. 1943;37:122-30.

76. McLaughlin RL. Search modes of birds and lizards: evidence for alternative movement patterns. Am Nat. 1989;133:654-70.

77. Abrahms B, Seidel DP, Dougherty E, Hazen EL, Bograd SJ, Wilson AM, et al. Suite of simple metrics reveals common movement syndromes across vertebrate taxa. Mov Ecol. 2017;5:12.

78. Johnson $\mathrm{DH}$. The comparison of usage and availability measurements for evaluating resource preference. Ecology. 1980;61:65-71.

79. Blake S, Yackulic CB, Cabrera F, Tapia W, Gibbs JP, Kümmeth F, et al. Vegetation dynamics drive segregation by body size in Galapagos tortoises migrating across altitudinal gradients. J Anim Ecol. 2013;82:310-21.

80. Gow EA, Wiebe KL. Males migrate farther than females in a differential migrant: an examination of the fasting endurance hypothesis. R Soc Open Sci 2014;1:140346-140346.

81. Patrick SC, Bearhop S, Grémillet D, Lescroël A, Grecian WJ, Bodey TW, et al. Individual differences in searching behaviour and spatial foraging consistency in a central place marine predator. Oikos. 2014;123:33-40.

82. Viswanathan GM, Afanasyev V, Buldyrev SV, Murphy EJ, Prince PA, Stanley HE. Lévy flight search patterns of wandering albatrosses. Nature. 1996;381:413-5.

83. Bonte D, Van Dyck H, Bullock JM, Coulon A, Delgado M, Gibbs M, et al. Costs of dispersal. Biol Rev. 2012;87:290-312

84. Huey RB, Pianka ER. Ecological consequences of foraging mode. Ecology. 1981;62:991-9.

85. Brönmark C, Skov C, Brodersen J, Nilsson PA, Hansson L-A. Seasonal migration determined by a trade-off between predator avoidance and growth. PLoS One. 2008;3:e1957.

86. Husting EL. Survival and breeding structure in a population of Ambystoma maculatum. Copeia. 1965;1965:352-62.

87. Gueron S, Levin SA, Rubenstein DI. The dynamics of herds: from individuals to aggregations. J Theor Biol. 1996;182:85-98.

88. Crofoot M, Harel B. Who Pays the Costs of Cohesion? Maintaining behavioral synchrony in baboon troops on the move. Cleveland, Ohio: Am J Phys Anthropol; 2019. p. 50-1.

89. Couzin ID, loannou CC, Demirel G, Gross T, Torney CJ, Hartnett A, et al. Uninformed individuals promote democratic consensus in animal groups. Science. 2011;334:1578-80.

90. del Mar Delgado M, Miranda M, Alvarez SJ, Gurarie E, Fagan WF, Penterian $V$, et al. The importance of individual variation in the dynamics of anima collective movements. Philos Trans R Soc B Biol Sci. 2018;373:20170008.

91. Mueller T, O'Hara RB, Converse SJ, Urbanek RP, Fagan WF. Social learning of migratory performance. Science. 2013;341:999-1002.

92. Simpson SJ, Sword GA, Lo N. Polyphenism in insects. Curr Biol. 2011;21:R738-49.

93. Baguette M. Long distance dispersal and landscape occupancy in a metapopulation of the cranberry fritillary butterfly. Ecography. 2003;26:153-60.

94. D'Aloia CC, Bogdanowicz SM, Francis RK, Majoris JE, Harrison RG, Buston PM. Patterns, causes, and consequences of marine larval dispersal. Proc Natl Acad Sci. 2015;112:13940-5.

95. Zaccara S, Crosa G, Vanetti I, Binelli G, Childress B, McCulloch G, et al. Lesser flamingo Phoeniconaias minor as a nomadic species in African shallow alkaline lakes and pans: genetic structure and future perspectives. Ostrich. 2011;82:95-100.

96. Shaw AK, Jalasvuori M, Kokko H. Population-level consequences of risky dispersal. Oikos. 2014:123:1003-13.

97. Bossenbroek JM, Kraft CE, Nekola JC. Prediction of long-distance dispersal using gravity models: Zebra mussel invasion of inland lakes. Ecol Appl. 2001;11:1778-88.
98. Sullivan LL, Li B, Miller TEX, Neubert MG, Shaw AK. Density dependence in demography and dispersal generates fluctuating invasion speeds. Proc Natl Acad Sci. 2017;114:5053-8.

99. Kot $M$, Lewis MA, van den Driessche $P$. Dispersal data and the spread of invading organisms. Ecology. 1996;77:2027-42.

100. Boulinier T, Kada S, Ponchon A, Dupraz M, Dietrich M, Gamble A, et al. Migration, prospecting, dispersal? What host movement matters for infectious agent circulation? Integr Comp Biol. 2016;56:330-42.

101. Berkley HA, Kendall BE, Mitarai S, Siegel DA. Turbulent dispersal promotes species coexistence. Ecol Lett. 2010;13:360-71.

102. Ricketts TH, Regetz J, Steffan-Dewenter I, Cunningham SA, Kremen C, Bogdanski A, et al. Landscape effects on crop pollination services: are there general patterns? Ecol Lett. 2008;11:499-515.

103. Wenny DG, Levey DJ. Directed seed dispersal by bellbirds in a tropical cloud forest. Proc Natl Acad Sci. 1998:95:6204-7.

104. Bauer S, Hoye BJ. Migratory animals couple biodiversity and ecosystem functioning worldwide. Science. 2014;344:1242552-1242552.

105. Krauss S, Stallknecht DE, Negovetich NJ, Niles LJ, Webby RJ, Webster RG. Coincident ruddy turnstone migration and horseshoe crab spawning creates an ecological 'hot spot' for influenza viruses. Proc R Soc B Biol Sci. 2010:277:3373-9.

106. Lisovski S, van Dijk JGB, Klinkenberg D, Nolet BA, Fouchier RAM, Klaassen M. The roles of migratory and resident birds in local avian influenza infection dynamics. J Appl Ecol. 2018;55:2963-75.

107. Post DM, Taylor JP, Kitchell JF, Olson MH, Schindler DE, Herwig BR. The role of migratory waterfowl as nutrient vectors in a managed wetland. Conserv Biol. 1998;12:910-20.

108. Subalusky AL, Dutton CL, Rosi EJ, Post DM. Annual mass drownings of the Serengeti wildebeest migration influence nutrient cycling and storage in the Mara River. Proc Natl Acad Sci. 2017:114:7647-52.

109. Gresh T, Lichatowich J, Schoonmaker P. An estimation of historic and current levels of salmon production in the Northeast Pacific ecosystem: evidence of a nutrient deficit in the freshwater systems of the Pacific northwest. Fisheries. 2000;25:15-21.

110. Snell-Rood EC. An overview of the evolutionary causes and consequences of behavioural plasticity. Anim Behav. 2013;85:1004-11.

111. Snell-Rood EC, Steck MK. Behaviour shapes environmental variation and selection on learning and plasticity: review of mechanisms and implications. Anim Behav. 2019;147:147-56.

112. Cwynar LC, MacDonald GM. Geographical variation of lodgepole pine in relation to population history. Am Nat. 1987;129:463-9.

113. Shine R, Brown GP, Phillips BL. An evolutionary process that assembles phenotypes through space rather than through time. Proc Natl Acad Sci. 2011;108:5708-11.

114. Phillips BL, Brown GP, Travis JMJ, Shine R. Reid's paradox revisited: the evolution of dispersal kernels during range expansion. Am Nat. 2008;172:S34-48.

115. Riotte-Lambert L, Matthiopoulos J. Environmental predictability as a cause and consequence of animal movement. Trends Ecol Evol. 2019; S0169534719302885.

116. Barros VR, Field CB, Dokken DJ, Mastrandrea MD, Mach KJ, Bilir TE, et al. Climate change 2014 impacts, adaptation and vulnerability. Part B: regional aspects. Working group II contribution to the fifth assessment report of the intergovernmental panel on climate change. New York, NY: Cambridge University Press; 2014.

117. Arcangeli A, Crosti R. The short-term impact of dolphin-watching on the behaviour of bottlenose dolphins (Tursiops truncatus) in western Australia. J Mar Anim Their Ecol. 2009:2:3-9.

118. Pavlacky DC, Possingham HP, Lowe AJ, Prentis PJ, Green DJ, Goldizen AW. Anthropogenic landscape change promotes asymmetric dispersal and limits regional patch occupancy in a spatially structured bird population. J Anim Ecol. 2012;81:940-52.

119. Brown LM, Hall RJ. Consequences of resource supplementation for disease risk in a partially migratory population. Philos Trans R Soc B Biol Sci. 2018; 373:20170095.

120. Lintermans M. Human-assisted dispersal of alien freshwater fish in Australia. N Z J Mar Freshw Res. 2004;38:481-501.

121. Hewitt N, Klenk N, Smith AL, Bazely DR, Yan N, Wood S, et al. Taking stock of the assisted migration debate. Biol Conserv. 2011;144:2560-72.

122. Le Galliard JF, Massot M, Clobert J. Dispersal and range dynamics in changing climates: a review. In: Clobert J, Baguette M, Benton TG, Bullock JM, editors. Dispersal Ecol Evol. Oxford: Oxford University Press; 2012. 
123. Dodd CK Jr, Cade BS. Movement patterns and the conservation of amphibians breeding in small, temporary wetlands. Conserv Biol. 1998;12:331-9.

124. Hogan JD, Blum MJ, Gilliam JF, Bickford N, Mclntyre PB. Consequences of alternative dispersal strategies in a putatively amphidromous fish. Ecology. 2014;95:2397-408.

125. Webster MS, Marra PP, Haig SM, Bensch S, Holmes RT. Links between worlds: unraveling migratory connectivity. Trends Ecol Evol. 2002;17:76-83.

126. Johnson DM, Liebhold AM, Tobin PC, Bjørnstad ON. Allee effects and pulsed invasion by the gypsy moth. Nature. 2006;444:361-3.

127. Gilroy JJ, Gill JA, Butchart SHM, Jones VR, Franco AMA. Migratory diversity predicts population declines in birds. Ecol Lett. 2016;19:308-17.

128. Miller TEX, Shaw AK, Inouye BD, Neubert MG. Sex-biased dispersal and the speed of two-sex invasions. Am Nat. 2011;177:549-61.

129. Shaw AK, Kokko H, Neubert MG. Sex difference and Allee effects shape the dynamics of sex-structured invasions. J Anim Ecol. 2018;87:36-46.

130. Bronstein JL. Our current understanding of mutualism. Q Rev Biol. 1994;69:31-51.

\section{Publisher's Note}

Springer Nature remains neutral with regard to jurisdictional claims in published maps and institutional affiliations.

Ready to submit your research? Choose BMC and benefit from:

- fast, convenient online submission

- thorough peer review by experienced researchers in your field

- rapid publication on acceptance

- support for research data, including large and complex data types

- gold Open Access which fosters wider collaboration and increased citations

- maximum visibility for your research: over $100 \mathrm{M}$ website views per year

At BMC, research is always in progress.

Learn more biomedcentral.com/submissions 